\title{
Cultura organizacional brasileira pós-globalização: global ou local?*
}

\author{
Rebeca Alves Chu** \\ Thomaz Wood Jr.***
}

SumÁRIo: 1. Introdução; 2. Revisão teórica; 3. Metodologia; 4. Apresentação dos resultados; 5. Discussão dos resultados; 6 . Comentários finais.

Summary: 1. Introduction; 2. Theorical review; 3. Methodology; 4. Presentation of the results; 5 . Discussion of the results; 6 . Final comments.

Palavras-chave: cultura organizacional; cultura nacional; traços culturais; hibridização; transição.

KEY WORDs: organizational culture; national culture; cultural traits; hybridization; transition.

Um dos grandes desafios para pesquisadores de gestão internacional é compreender a diversidade institucional e cultural dos ambientes de negócios nacionais. Para responder a tal desafio, os pesquisadores recorrem a agrupamentos e generalizações. Embora tal recurso metodológico apresente inegáveis méritos, pode prover quadros relativamente pobres sobre a realidade de cada país. Este artigo procura endereçar essa lacuna. Realizamos uma pesquisa exploratória sobre os traços da cultura organizacional brasileira hoje, após 17 anos de abertura econômica e transformações institucionais, as quais geraram profundos impactos na sociedade e nas organizações. Exploramos a literatura existente sobre traços da cultura organizacional brasileira e apresentamos um estudo de campo baseado em entrevistas com profissionais es-

* Artigo recebido em dez. 2007 e aceito em maio 2008.

**Bacharel e mestre em administração de empresas pela Fundação Getulio Vargas/Escola de Administração de Empresas de São Paulo (FGV/Eaesp). Professora da Business School de São Paulo. Endereço: E-mail: rebeca.chu@prof.bsp.edu.br.

***Bacharel em engenharia química pela Universidade de Campinas (Unicamp), mestre e doutor em administração de empresas pela Fundação Getulio Vargas/Escola de Administração de Empresas de São Paulo (FGV/Eaesp). Professor da FGV/Eaesp. Endereço: E-mail: thomaz.wood@fgv.br. 
trangeiros que trabalham no Brasil e com profissionais brasileiros que já trabalharam fora do país. A comparação entre os estudos anteriores e o presente estudo revela um quadro híbrido, transitório e com ressignificações, típico de um período de transição marcado pela convivência entre traços pré-globalização e traços pós-globalização.

Brazilian cultural organization in post-globalization: global or local?

A great challenge facing international management researchers is understanding the institutional and cultural diversity of national business environments. In response to this challenge, researchers often resort to pooling and generalizations. Despite the undeniable merits of such a methodological approach, it may provide relatively poor descriptions of each country's reality. The purpose of this article is to address this gap. We carried out an exploratory research of Brazil's organizational culture today, after 17 years of economic openness and institutional changes that have led to deep impacts on society and organizations. We explored the existing literature on traits of Brazil's organizational culture and present a field study based on interviews with foreign professionals working in Brazil and with Brazilian professionals with overseas experience. Comparison of the present study with previous ones shows a hybrid picture typical of a transition period marked by the coexistence of pre-and post-globalization traits.

\section{Introdução}

O impacto de culturas nacionais sobre a gestão das empresas tem sido objeto constante de trabalhos científicos. Diferentes autores desenvolveram diferentes abordagens conceituais e esquemas classificatórios, em função de distintas dimensões ou variáveis escolhidas (Adler, 2002; Emrich, Denmark e Hartog, 2004; Hall, 1959; 1960; 1977; Hofstede, 1997; 2001; House e co-autores, 2004; Kabasal e Bodur, 2004; Laurent, 1981; Trompenaars, 1993).

Trabalhos deste tipo realizados no Brasil têm se apoiado com freqüência em investigações sobre a formação histórica, cultural, social e econômica do país (Barros e Prates, 1996; Freitas, 1991; Motta, 1996; Vergara, Moraes e Palmeira, 1997; Wood e Caldas, 2002). O esforço de investigação é permanente, em função do caráter mutável do objeto. Traços culturais constituem variáveis dinâmicas, que sofrem influências do meio socioinstitucional e, por sua vez, interferem nos processos de gestão das empresas.

No Brasil, a abertura econômica ocorrida a partir dos anos 1990 foi acompanhada de reformas econômicas estruturais, a compreender programas amplos de desregulamentação econômica e de privatização. O processo tam- 
bém provocou um aumento dos investimentos estrangeiros no país e levou as empresas locais a buscarem iniciativas de consolidação (por meio de processos de fusão e aquisição) e a implementação de programas de atualização tecnológica e de modernização da gestão.

Tal processo foi ainda acompanhado pelo aumento do fluxo de profissionais expatriados (do exterior para o Brasil e do Brasil para o exterior) e pela difusão de novas práticas de gestão disseminadas pela mídia de negócios, pelas empresas de consultoria e pelas escolas de gestão. De forma geral, o país se mostrou receptivo à importação de novas práticas de gestão, que foram adaptadas e adotadas (Wood e Caldas, 2002). Para os gestores locais, o desafio que se colocou foi responder às pressões pela adoção dessas práticas internacionais e, simultaneamente, respeitar as peculiaridades culturais e institucionais locais.

Este artigo contribui para a sistematização do quadro sobre traços da cultura organizacional brasileira. O texto está estruturado da seguinte forma: na próxima seção, sistematizamos a literatura existente sobre traços culturais nacionais e traços da cultura organizacional brasileira; na seção seguinte, apresentamos a metodologia da investigação de campo; em seguida são apresentados os resultados do estudo empírico; na seção posterior, discutimos o caráter híbrido e de transição dos traços da cultura organizacional brasileira; e na seção final indicamos implicações para a prática gerencial.

\section{Revisão teórica}

\section{Culturas nacionais}

O impacto das culturas nacionais na gestão das organizações tem sido alvo constante de estudos científicos. Grande parte desses estudos analisa as culturas nacionais em função de três grandes grupos de variáveis. O primeiro diz respeito a como a organização se adapta ao ambiente, considerando para isso o relacionamento que possui com a incerteza (Hofstede, 1997, 2001; House e co-autores, 2004). O segundo grupo diz respeito à integração interna da organização, por meio da análise de fatores como o grau de orientação para tarefas ou pessoas, grau de hierarquia, feminilidade e masculinidade, individualismo e coletivismo, entre outras variáveis (Kabasal e Bodur, 2004; Trompenaars, 1993; House e co-autores, 2004; Hofstede, 1997, 2001). O terceiro relacionase às questões do espaço, do tempo e da linguagem (Hall, 1959, 1960, 1977; Hofstede, 1997, 2001). Esses estudos mostram que as culturas nacionais dife- 
rem quanto aos pressupostos culturais existentes e demonstram, conseqüentemente, valores, comportamentos e artefatos distintos.

A cultura nacional brasileira é compreendida, por esses estudos, como de elevada distância de poder, com comportamentos mais coletivistas do que individualistas e com alta necessidade de evitar incertezas. Seria também uma cultura levemente inclinada a valores femininos, com baixa orientação à performance, orientação ao curto prazo e policrônica (Kabasal e Bodur, 2004; Hofstede, 1997, 2001).

\section{Cultura organizacional brasileira}

No Brasil, a maior parte dos estudos que objetivam compreender o impacto dos traços da cultura brasileira na gestão das organizações se apóia em trabalhos sobre a formação histórica, cultural, social e econômica do país. Tais estudos foram produzidos na década de 1990 e revelam uma diversidade grande de traços culturais nacionais que caracterizam a forma como as organizações são geridas no país (Motta e Caldas, 1997; Barros e Prates, 1996; Freitas, 1997; Barros e Prates, 1996; Davel e Vasconcelos, 1997; Matheus, 1997; Costa, 1997; Vergara, Moares e Palmeira, 1997; Motta, 1996; Wood e Caldas, 1998; Caldas, 1997; Motta, Alcadipani e Brasler, 2001). Os estudos variam com relação à metodologia utilizada e ao escopo proposto. No entanto, é possível perceber as seguintes tendências ou características marcantes: primeiro, a incorporação de estudos locais realizados por reconhecidos antropólogos, economistas e sociólogos locais como Gilberto Freire, Sérgio Buarque de Holanda, Caio Prado Junior e Roberto DaMatta; segundo, a influência do esquema classificatório de Hofstede $(1997,2001)$; e terceiro, a tentativa de retratar a cultura organizacional local por meio da identificação e análise de traços culturais marcantes.

A revisão desses estudos possibilitou a visualização de que os elementos utilizados pelos autores para definição dos traços culturais que permeiam as organizações no Brasil e que definiriam a forma como a gestão é praticada no país são muitas vezes coincidentes ou semelhantes. Por isso, são colocados a seguir seis traços essenciais e centrais da cultura organizacional brasileira tratados nesses estudos:

$\checkmark$ jeitinho - comportamento que visa à harmonização das regras e determinações universais da vida com as necessidades diárias do cidadão, buscando a realização de objetivos a despeito de determinações legais contrárias. 
Revela um "combate" entre leis universais e relações pessoais. Segundo antropólogos brasileiros (Barbosa, 1992; DaMatta, 1991) o jeitinho brasileiro é uma estratégia para suavizar as formas impessoais que regem as relações pessoais. O jeitinho é ambíguo e admite dupla leitura, pode significar uma postura conformista de convivência com o status quo injusto e inaceitável; e pode ser visto como uma forma de sobreviver ao cotidiano, um recurso de resistência cultural;

- desigualdade de poder e hierarquia - o sistema de relações hierárquicas que vigorou nas relações entre senhor e escravo no Brasil colonial marcou profundamente a sociedade local. Em sociedades como a norte-americana tem-se como pressuposto que todo cidadão é igual perante a sociedade e a lei. No Brasil, muitos indivíduos julgam-se com direitos especiais que os eximem de sujeitar-se à lei de caráter generalizante. A expressão popular "você sabe com quem está falando?" é comumente ouvida em situações de conflito e revela uma reação autoritária, que tenta impor uma condição especial. A desigualdade de poder enraizada na cultura brasileira e na cultura organizacional brasileira revela a força da hierarquia nas relações entre as pessoas e a grande importância dada ao status individual e à autoridade dos superiores (Motta, 1996; Barros e Prates, 1996; Freitas, 1997);

$\checkmark$ flexibilidade - a flexibilidade que permeia os comportamentos nas organizações no país traduz-se na capacidade de adaptação e criatividade das pessoas. A adaptação refere-se à capacidade de ajuste a situações diversas e a criatividade refere-se à capacidade de inovação. Dentro das organizações esse aspecto emerge da capacidade histórica das organizações e indivíduos de adaptação a diversas e difíceis situações econômicas e às múltiplas práticas e ferramentas de administração trazidas de outros contextos de gestão (Barros e Prates, 1996);

v plasticidade - tem como raiz o gosto pela miscigenação, pelo novo e pelo exótico, que marcou a colonização do país. O colonizador português se distinguia de outros colonizadores pela ausência do orgulho de raça, por forte atração pelo sensual e pelo exótico e pelo gosto pela mistura racial. A plasticidade manifesta-se pela assimilação fácil de práticas e costumes estrangeiros e revela a propensão a mirar modelos e conceitos desenvolvidos em outros contextos de gestão em detrimento daqueles desenvolvidos localmente. Histórica e tradicionalmente a adoção de conceitos e referenciais estrangeiros na gestão das organizações no Brasil é feita sem críticas, o que revela o alto grau de permeabilidade da nação àquilo que é desenvolvido lá 
fora. Entretanto, é necessário ressaltar que tal assimilação pode ocorrer em alguns casos apenas superficialmente, enganando um observador menos atento e indicando um comportamento de fachada (Wood e Caldas, 1998; Caldas, 1997; Motta, Alcadipani e Bresler, 2001; Bertero e Keinert, 1994);

$\checkmark$ personalismo - expressa a importância atribuída às pessoas e aos interesses pessoais em detrimento das pessoas ou interesses do grupo ou comunidade. Indica o alto grau de confiança depositado na rede de amigos e familiares para resolução de problemas ou obtenção de privilégios. A expressão popular local "para os amigos tudo, para os inimigos nada, para os indiferentes a lei" atribuída a uma importante figura política do século XX exemplifica esse traço. No Brasil, a aplicação restrita da lei é reservada ao cidadão anônimo, isolado e sem relações (Barros e Prates, 1996 ; Freitas, 1997; Motta, 1996);

v formalismo - se traduz nas organizações por meio de comportamentos que buscam por um lado a redução do risco, da ambigüidade e da incerteza e, por outro, aumento de previsibilidade e controle sobre as ações e comportamentos humanos. Essa busca se dá por meio da criação de grande quantidade de regras, normas e procedimentos que visam garantir segurança. Ou seja, esse traço está presente no apego a leis e regras e pode provocar discrepâncias entre o que é escrito e o que é realizado ou entre o que é dito e o que é de fato feito. Na prática, tal condição implica a multiplicação das atividades de controle (Barros e Prates, 1996; Motta e Alcadipani, 1999).

A análise dos estudos que buscaram compreender o impacto da cultura brasileira na gestão das organizações no país possibilitou também a visualização de traços mais periféricos à cultura organizacional brasileira que, embora não centrais nesses estudos, acabam por finalizar a composição dos traços que caracterizam a cultura organizacional brasileira e a forma como a gestão é praticada no país. A seguir esses traços são comentados breve e sucintamente.

A gestão no Brasil é levemente mais orientada a valores femininos como cuidado com o próximo, igualdade, bem-estar, qualidade de vida — do que masculinos - como agressividade, assertividade, resultados, performance, entre outros (Urdan e Urdan, 2001; Alcadipani e Crubellate, 2003). A orientação para ação e planejamento organizacional é reduzida. O tempo é gerido com ineficiência e a orientação predominante é para o curto prazo. Da grande distância de poder entre as pessoas derivam os traços do autoritarismo - excesso de respeito e submissão à figura de poder — do desconforto diante de conflitos abertos e da postura de expectador (Barros e Prates, 1996). Adi- 
cionalmente, o Brasil é visto como um país cujos indivíduos e organizações apresentam frequentemente comportamentos cordiais, ou seja, comportamentos permeados pela aparência afetiva, mas não necessariamente sinceros ou profundos. Traduz-se na reduzida capacidade de dizer "não" (Costa, 1997).

\section{Contexto de gestão brasileiro}

O Brasil viveu a partir da década de 1990 seu processo de abertura comercial e econômica. Tal processo foi acompanhado de reformas estruturais, programas de desestatização e privatização, quebra de monopólios e necessidade de modernização institucional e tecnológica. Investimentos estrangeiros foram incentivados, bem como a entrada de multinacionais no país. Nesta época, o país: viveu uma multiplicação intensa de processos de fusões e aquisições (Barros e Cançado, 2005; Trinches, 1996; Miranda e Martins, 2000); mostrouse receptivo a referenciais e modelos de gestão internacionais disseminados em função da globalização (Wood e Caldas, 2002; Wood e Caldas, 1998); presenciou um aumento do fluxo de expatriados brasileiros para fora do país e de estrangeiros para dentro de suas fronteiras (Gonçalves e Miura, 2002; Homem e Tolfo, 2004; Elis e Carrieri, 2005); e presenciou também a proliferação de cursos de MBA locais que refletiam um conteúdo preponderantemente estrangeiro (Wood e Paes de Paula, 2002).

A busca por inserção e participação na economia mundial introduziu ao contexto de gestão local referências, modelos e práticas de gestão estrangeiros que impactaram a cultura organizacional brasileira e a forma como a gestão passou a ser feita no país. Esses referenciais e modelos estrangeiros permearam as organizações misturando-se e fundindo-se com os valores, práticas e ferramentais originariamente brasileiros. O contexto de gestão local foi, portanto, nas últimas décadas, fortemente exposto a referenciais estrangeiros de gestão que permearam e influenciaram a prática da gestão no país (Caldas, 1997).

\section{Homogeneização ou hibridização?}

Um debate que surge a partir dos efeitos da globalização e da internacionalização dos negócios diz respeito à influência paralela dos valores e referenciais locais na constituição de culturas organizacionais e de práticas de gestão características de uma nação. A visão tradicional de globalização está 
ligada a processos de homogeneização. Uma visão mais crítica e provocadora, no entanto, convida à percepção da globalização como um processo impulsionador de heterogeneidade. A noção de heterogeneidade relaciona-se, por sua vez, com processos de hibridização. Nesse sentido, a globalização e processos de hibridização passam a ser vistos como simultâneos, oferecendo a possibilidade de desenvolvimento de mesclas culturais "translocais" (Pieterse, 1994; Burke, 2003).

O estudo de movimentos de hibridização torna-se parte indispensável deste trabalho na medida em que oferece um arcabouço teórico sólido e atual para a discussão dos traços da cultura organizacional brasileira em função das forças e impactos da globalização e internacionalização nos negócios. A seguir, retomam-se alguns aspectos teóricos sobre as origens e significados dos termos relacionados a processos de hibridização, sobre hibridização nos estudos culturais e sobre híbridos culturais. A síntese dos aspectos teóricos a seguir foi realizada com base no trabalho de Steuer (2006).

O termo híbrido parece ter sido relacionado primeiramente à questão de identidade organizacional híbrida, transmitindo a idéia organizacional na qual haveria justaposição de sistemas de valores aparentemente antagônicos (Albert e Whetten, 1985). O termo foi empregado por Borys e Jemison (1989) também para designar arranjos organizacionais compostos de esquemas, recursos e estruturas de outras organizações. Foi também utilizado por Schein (1992) para definir indivíduos socializados em uma determinada organização e que exercem a função de gestão em outra organização socialmente distinta.

Já o termo hibridismo, de uma maneira bastante ampla, relaciona-se a processos coletivos de interação de culturas (cultura entendida aqui como atitudes, valores, mentalidades e suas expressões organizacionais). Mais especificamente, ele remete a um processo de identificação simultânea de elementos de culturas anteriormente distintas que resulta em uma nova configuração cultural a partir do encontro dessas culturas (Burke, 2003; Canclini, 2003). Tomando como base a perspectiva pós-moderna, as organizações hoje seriam compostas de "fragmentos" - ou hibridismos - cujas composições evidenciariam a convivência de realidades e discursos pré-modernos, modernos e pós-modernos (Boje, 2002).

A noção de hibridização, dentro dos estudos culturais, diz respeito a formas de interação cultural que implicam a justaposição e a combinação de elementos como produtos ou tecnologias de diferentes épocas ou mesmo de processos sociais pré-modernos, modernos e pós-modernos (Canclini, 2003). Ainda dentro dos estudos culturais, o termo foi relacionado, no caso do Brasil, ao movimento de "importação" de referenciais estrangeiros que pos- 
sui como resultado a convivência de elementos do local com elementos do estrangeiro (Wood e Caldas, 1998). Hibridização também esteve relacionada a processos de mudança organizacional nos quais a substituição de sistemas não ocorre, dando lugar a uma formação social fragmentada, heterogênea e múltipla (Calás e Arias, 1997). Alguns exemplos de formações organizacionais híbridas são os abrigos de proteção contra a violência doméstica (misturam o racional burocrático com a prática feminista), as entidades que combinam elementos da administração pública com características de empresas privadas com fins lucrativos e as organizações que combinam aspectos democráticos e burocráticos. Essas seriam típicas organizações resultantes de "mesclas lógicas" ou híbridos organizacionais (Ashcraft, 2001).

Neste artigo será adotada a definição de hibridização organizacional de Steuer (2006). Para ela, a hibridização organizacional é vista como "processo de transformação da formação social em que se verifica o surgimento de novas configurações e fragmentos organizacionais únicos, em movimento contínuo, derivado da tensão entre forças de origens e direções variadas".

\section{Metodologia}

O estudo empírico seguiu a abordagem geral adotada por Cunha (2005) em estudo similar. Com o objetivo de atualizar o quadro de traços da cultura organizacional brasileira foi realizada uma pesquisa qualitativa e exploratória com executivos da cidade de São Paulo. A escolha por essa cidade se deu por ela ser o principal e mais cosmopolita centro empresarial do Brasil.

A abordagem qualitativa do estudo foi adotada em função da aderência e coerência que possui em relação aos objetivos do artigo, o que permite a compreensão da complexidade das interações sociais expressas na vida cotidiana e do significado que as pessoas atribuem a elas. É uma abordagem fundamentada nas experiências vividas pelas pessoas. O estudo possui ainda caráter exploratório na medida em que seu propósito é compreender e descrever como se caracterizam atualmente os traços culturais da gestão das organizações no país (Marshal e Rossman, 1999; Creswell, 2003).

A coleta dos dados foi realizada por meio de entrevistas semi-estruturadas que tiveram duração de 60 a 90 minutos. O roteiro compreendeu questões como os aspectos mais difíceis e mais fáceis da gestão no Brasil, as habilidades necessárias ao gestor, os desafios impostos pelo contexto local de negócios, as diferenças entre a gestão no Brasil e em outros países e a adoção 
de referenciais estrangeiros. Todas as entrevistas foram gravadas e transcritas na íntegra.

Os entrevistados foram escolhidos com base em dois critérios: possuir experiência de gestão no Brasil e experiência de gestão fora do Brasil. Foram entrevistados 16 brasileiros e nove estrangeiros, com idades entre 24 e 60 anos e um mínimo de três anos de experiência de trabalho. A quantidade de entrevistados brasileiros e estrangeiros não foi previamente definida. Optamos por considerar quantidade adequada aquela a partir da qual os temas tornaram-se intensamente recorrentes. A maior parte dos entrevistados teve formação em administração de empresas ou engenharia, era do sexo masculino e trabalhava em empresas de grande porte de origem internacional. Os ramos de atividade das empresas eram variados, com um leve predomínio do ramo de consultoria.

Uma análise de conteúdo foi efetuada sobre as entrevistas e a técnica utilizada foi análise categorial temática (Bardin, 1977). Para isso, os textos transcritos de todas as entrevistas foram divididos em temas que, por meio de reagrupamentos analógicos, foram classificados em categorias temáticas. O método de análise se dividiu em duas etapas: primeiro foram identificados temas, constituídos por enunciados ou trechos dos textos transcritos que portavam significações que pudessem ser isoladas (Bardin, 1977); e segundo, foram formadas categorias temáticas. O critério para constituição das categorias foi semântico. Por isso, os temas com mesmo significado e que remetiam ao mesmo conceito foram reunidos na mesma categoria. É importante ressaltar que as categorias formadas são mutuamente excludentes, homogêneas em si e pertinentes ao objetivo do estudo e que os traços culturais apontados na revisão teórica — tanto os centrais quanto os periféricos — serviram como "guias" para a formação e análise das categorias da cultura brasileira nas organizações, apresentados e comentados a seguir.

\section{Apresentação dos resultados}

A partir da análise da investigação de campo serão apresentadas a seguir as características marcantes de cada uma das categorias ou traços culturais. Tais características indicam uma síntese da percepção que os entrevistados possuem sobre a cultura organizacional brasileira e a forma como a gestão é pratica no país atualmente. As evidências empíricas ilustram as características apresentadas para cada traço cultural e estão apontadas no quadro 1. Primeiramente são apresentadas as características marcantes dos traços tidos como 
centrais na literatura existente e em seguida aquelas dos traços tidos como periféricos.

\section{Traços culturais centrais}

O jeitinho brasileiro é em geral percebido como algo negativo ao país, embora possa ser útil e benéfico para indivíduos isoladamente. Ele é percebido como um comportamento pouco profissional ou até mesmo amador. Gera para o país um sentimento de instabilidade e de falta de credibilidade nas instituições que o governam.

Sobre o traço da desigualdade de poder, os relatos indicam que a noção de igualdade entre as pessoas é reduzida e como conseqüência há grande distância entre os níveis hierárquicos. A percepção geral é a de que quando as pessoas alcançam a gerência média elas tendem a se acomodar na posição e sentem-se confortáveis com o poder e o status que a posição lhes atribui.

A percepção de que os brasileiros são flexíveis, criativos e se ajustam facilmente a situações inesperadas esteve bastante presente nos depoimentos. O gestor brasileiro é versátil, como alguém que busca criatividade nas ações diárias e que se mostra confortável diante de mudanças freqüentes.

Os depoimentos obtidos sugerem que as empresas no Brasil espelhamse fortemente em referências de gestão estrangeiras, isto é, desenvolvidas em outros contextos de gestão. Sugerem, também, que embora o espelhamento seja forte, muitos gestores adotam esses referenciais com posturas e visões críticas. Outra característica marcante nos depoimentos sobre a relação dos brasileiros e organizações no país com os referenciais estrangeiros foi a percepção da necessidade de valorização das práticas nacionais. Diversos depoimentos ressaltaram que ferramentas, práticas e modelos desenvolvidos no país tornaram-se referências em outros contextos de gestão.

O traço do personalismo revelou-se presente na gestão das organizações no país por meio das seguintes características marcantes: as pessoas buscam relacionamentos próximos e afetivos no ambiente de trabalho, o que torna os relacionamentos pessoais por vezes mais importantes do que as competências técnicas; o relacionamento pessoal seria fundamental para a eficiência e produtividade do trabalho em grupo; e a qualidade dos relacionamentos pessoais no ambiente de trabalho é determinadora da qualificação desse ambiente como bom ou não para se trabalhar. Os depoimentos indicam que, de maneira geral, os relacionamentos profissionais tendem a ser também pessoais. 
Por fim, com relação à categoria do formalismo, os depoimentos indicam que no dia-a-dia da gestão a tolerância a normas, regras e procedimentos formalizados é reduzida e que haveria, conseqüentemente, pouca sistematização e padronização das atividades realizadas. No entanto, os relatos sobre o formalismo sugerem que essa pouca tolerância à sistematização e padronização tende a crescer com o impacto das mudanças decorrentes da abertura comercial e econômica do país e com a internacionalização dos negócios.

\section{Traços culturais periféricos}

Os relatos dos entrevistados revelam que a orientação a resultados financeiros se torna um elemento cada vez mais presente nas organizações no país. Em geral, reconhece-se a predominância de uma orientação mais humana, no entanto, os entrevistados percebem a crescente preocupação com relação à performance e aos resultados. Isso aconteceria em função da abertura do país à economia em crescente internacionalização.

Em relação ao planejamento e à orientação à ação os relatos indicam que, em função da instabilidade política e econômica histórica no país, há falta de planejamento e estruturação das ações nas organizações. No entanto, também em função da abertura à internacionalização dos negócios, o planejamento das atividades organizacionais tem crescido em termos históricos - embora comparativamente a outros países ainda haveria muito a se evoluir. Para os entrevistados, o gestor brasileiro ainda é alguém que gerencia seu tempo de maneira ineficiente, possui dificuldades para cumprir prazos e foca seu trabalho no curto prazo.

Outro traço marcante da gestão no Brasil é o autoritarismo. As pessoas comportam-se de maneira predominantemente submissa e fazem o que lhes é dito para fazer. Há pouco desafio a ordens e excesso de respeito à autoridade. Ainda segundo os relatos, as decisões no país tendem a caminhar para o consenso, pois há muito medo do confronto, ausência de críticas e pontos de vistas dissidentes, revelando grande tendência à aversão ao conflito.

$\mathrm{O}$ traço da postura de expectador mostrou-se presente nos depoimentos por meio de características como transferência e diluição de responsabilidades, falta de autodeterminação para realização das tarefas e preferência pela tomada de decisão nas instâncias e posições superiores. Por fim, os relatos indicam que a cordialidade está presente por meio de comportamentos aparentemente amáveis e simpáticos, mas que não traduzem as reais intenções. Isso estaria muito ligado à dificuldade em dizer "não". 
Dos depoimentos colhidos, é possível destacar ainda três características marcantes sobre as mudanças na esfera nacional e internacional que impactam a cultura organizacional nacional e a gestão praticada hoje. A primeira diz respeito ao ambiente institucional que é predominantemente instável, complexo e de difícil compreensão. No entanto, na visão dos entrevistados, ele tem se tornado mais sólido política e economicamente, mais previsível e menos volátil econômica e financeiramente. A segunda destaca a importância e o peso da abertura comercial e econômica do país, da entrada de multinacionais e de referenciais estrangeiros e da modernização das empresas. A terceira aponta a grande diferença existente na formação e na composição dos gestores brasileiros nas organizações. Há, por um lado, uma geração mais antiga, com formação e visão de gestão anterior à abertura econômica e, por outro, uma geração atual, mais moderna, internacionalizada e cosmopolita. O quadro 1 aponta alguns dos depoimentos realizados para cada traço cultural.

\section{Quadro 1 \\ Depoimentos por traço cultural}

\begin{tabular}{|c|c|}
\hline Traço cultural & Depoimento(s) \\
\hline Jeitinho & $\begin{array}{l}\text { "Acho que o jeitinho brasileiro é positivo para os profissionais, mas negativo para o } \\
\text { país" e "o jeitinho brasileiro é um problema... a questão de burlar as coisas... isso } \\
\text { gera instabilidade". }\end{array}$ \\
\hline $\begin{array}{l}\text { Desigualdade } \\
\text { de poder e } \\
\text { hierarquia }\end{array}$ & $\begin{array}{l}\text { "O que eu percebi quando cheguei aqui no Brasil é uma grande diferença entre o } \\
\text { middle e o top management" e "o brasileiro é muito ligado a status... o brasileiro é } \\
\text { muito seduzido pelo poder". }\end{array}$ \\
\hline Flexibilidade & $\begin{array}{l}\text { "Você decide rápido, está acostumado a mudar. O brasileiro está acostumado, entra } \\
\text { crise, sai crise. Isso leva à adaptabilidade" e "o brasileiro gosta de atalhos, é criativo, } \\
\text { isso é vantajoso". }\end{array}$ \\
\hline Plasticidade & $\begin{array}{l}\text { "As pessoas tendem a olhar para o que é de fora com respeito... as melhores práticas } \\
\text { estão lá... só que, ao mesmo tempo, as pessoas têm um pouco de pé atrás... isso } \\
\text { é lá fora, não vai necessariamente funcionar aqui" e "a gente tem o mito de que o } \\
\text { estrangeiro é melhor do que a gente. Isso existe". }\end{array}$ \\
\hline Personalismo & $\begin{array}{l}\text { "Aqui você vai até certo nível com política e de um nível pra baixo é amizade pura. E você } \\
\text { faz negócio só porque é amigo mesmo"; e "eu prefiro o estilo brasileiro de trabalhar. De } \\
\text { você no cafezinho poder falar sobre futebol... acho importante. Impacta tua produtividade } \\
\text { no trabalho" e "acho que ao trazer a vida pessoal para o trabalho, sua vida fica melhor. } \\
\text { Porque você compartilha com as pessoas. Você até melhora seu trabalho". }\end{array}$ \\
\hline Formalismo & $\begin{array}{l}\text { "Em outros lugares tudo funciona com normas e procedimentos. No Brasil é tudo } \\
\text { mais informal. Aqui vai-se aos trancos e barrancos" e "acho que talvez seja uma } \\
\text { mudança de contexto, mas as empresas brasileiras hoje levam a sério a formalização, } \\
\text { a padronização dos processos... estão mais preocupadas com isso hoje do que esta- } \\
\text { vam há cinco anos atrás". }\end{array}$ \\
\hline
\end{tabular}

Continua 


\begin{tabular}{|c|c|}
\hline Traço cultural & Depoimento(s) \\
\hline $\begin{array}{l}\text { Orientação para } \\
\text { resultados }\end{array}$ & "Acho que o profissional no Brasil de hoje tem uma orientação a resultados." \\
\hline $\begin{array}{l}\text { Orientação para } \\
\text { ação/planeja- } \\
\text { mento }\end{array}$ & $\begin{array}{l}\text { "Estamos evoluindo, mas em termos comparativos com outros países, acho que } \\
\text { ainda tem muito para desenvolver" e "acho que estamos evoluindo, por isso que } \\
\text { o planejamento nas empresas está ganhando força. Se você olhar, o planejamento } \\
\text { está, cada vez mais, aumentando o seu espaço". }\end{array}$ \\
\hline $\begin{array}{l}\text { Gestão do } \\
\text { tempo }\end{array}$ & $\begin{array}{l}\text { "As pessoas [no Brasil] têm hora pra começar uma reunião, mas não têm hora pra } \\
\text { terminar. Eles começam falando uma coisa, vão para outra e outra e talvez voltem } \\
\text { para o assunto inicial." }\end{array}$ \\
\hline Autoritarismo & $\begin{array}{l}\text { "É difícil para os brasileiros desafiarem o que alguém está dizendo, particularmente } \\
\text { se essa pessoa é hierarquicamente superior" e "o brasileiro não necessariamente vai } \\
\text { sair fazendo. Ele vai pedir autorização primeiro." }\end{array}$ \\
\hline $\begin{array}{l}\text { Aversão ao } \\
\text { conflito }\end{array}$ & "O brasileiro odeia conflito. Faz o que for preciso para evitar." \\
\hline $\begin{array}{l}\text { Postura de } \\
\text { expectador }\end{array}$ & $\begin{array}{l}\text { "Aqui no Brasil as pessoas contam com o fato de que as pessoas em cargos impor- } \\
\text { tantes é que vão tomar as decisões." }\end{array}$ \\
\hline Cordialidade & $\begin{array}{l}\text { "As pessoas [no Brasil] dizem ah sim, muito interessante, vou pensar no assunto, } \\
\text { vamos falando... a mensagem não é clara." }\end{array}$ \\
\hline
\end{tabular}

\section{Discussão dos resultados}

Os quadros 2 e 3 sintetizam a situação de cada traço cultural, apontando as características "pré-globalização" e abertura econômica e comercial (visão anterior) e as características "pós-globalização" obtidas na investigação de campo (visão atual). A análise de ambos os quadros revela que a visão atual de alguns traços é mantida, enquanto outros apresentam sinais de enfraquecimento ou mudança (ressignificação).

\section{Quadro 2 \\ Mudanças nos traços culturais centrais}

\begin{tabular}{|lll|}
\hline Categoria & \multicolumn{1}{c|}{$\begin{array}{c}\text { Visão anterior } \\
\text { (pré-globalização) }\end{array}$} & \multicolumn{1}{c|}{$\begin{array}{c}\text { Visão atual } \\
\text { (pós-globalização) }\end{array}$} \\
\hline Jeitinho & $\begin{array}{l}\text { Flexibilidade e criatividade diante de } \\
\text { barreiras ou situaçães imprevistas. }\end{array}$ & $\begin{array}{l}\text { Ressignificação, com visão crítica: jeitinho } \\
\text { como comportamento pouco profissional } \\
\text { ou amador. }\end{array}$ \\
$\begin{array}{ll}\text { Desigualdade } \\
\text { do poder e } \\
\text { hierarquia }\end{array}$ & $\begin{array}{l}\text { Grande distância de poder entre } \\
\text { indivíduos; prevalência de hierar- }\end{array}$ & $\begin{array}{l}\text { Manutenção do traço: distância entre média } \\
\text { a alta gerência; valorização do status quo e } \\
\text { acomodação nas posições. }\end{array}$ \\
\hline
\end{tabular}




\begin{tabular}{|c|c|c|}
\hline Categoria & $\begin{array}{c}\text { Visão anterior } \\
\text { (pré-globalização) }\end{array}$ & $\begin{array}{c}\text { Visão atual } \\
\text { (pós-globalização) }\end{array}$ \\
\hline Flexibilidade & $\begin{array}{l}\text { Capacidade de adaptação e criati- } \\
\text { vidade; ajuste a diversas situações } \\
\text { e capacidade de inovação; versati- } \\
\text { lidade. }\end{array}$ & $\begin{array}{l}\text { Manutenção do traço: flexibilidade para mu- } \\
\text { danças freqüentes; gestor brasileiro versátil; } \\
\text { criatividade para soluções inesperadas. }\end{array}$ \\
\hline Plasticidade & $\begin{array}{l}\text { Fascínio com teorias e métodos } \\
\text { importados. }\end{array}$ & $\begin{array}{l}\text { Manutenção do traço, porém com tendên- } \\
\text { cia a apreciações críticas e a valorização de } \\
\text { práticas locais (nova nuança). }\end{array}$ \\
\hline Personalismo & $\begin{array}{l}\text { Valorização das relaçães pessoais } \\
\text { em relação às competências téc- } \\
\text { nicas. }\end{array}$ & Manutenção do traço. \\
\hline Formalismo & $\begin{array}{l}\text { Valorização de regras e procedimen- } \\
\text { tos burocráticos; comportamentos } \\
\text { de fachada e faz-de-conta. }\end{array}$ & $\begin{array}{l}\text { Ressignificação: reconhecimento da impor- } \\
\text { tância da adoção de padrões operacionais e } \\
\text { gerenciais superiores }\end{array}$ \\
\hline
\end{tabular}

\section{Mudanças nos traços culturais periféricos}

\begin{tabular}{|c|c|c|}
\hline Categoria & $\begin{array}{l}\text { Visão anterior } \\
\text { (pré-globalização) }\end{array}$ & $\begin{array}{c}\text { Visão atual } \\
\text { (pós-globalização) }\end{array}$ \\
\hline $\begin{array}{l}\text { Orientação para } \\
\text { resultados }\end{array}$ & $\begin{array}{l}\text { Foco na tarefa e no processo; foco } \\
\text { secundário no resultado. }\end{array}$ & $\begin{array}{l}\text { Ressignificação: preocupação crescente com } \\
\text { o desempenho e foco em metas. }\end{array}$ \\
\hline $\begin{array}{l}\text { Orientação para } \\
\text { a ação/planeja- } \\
\text { mento }\end{array}$ & $\begin{array}{l}\text { Ênfase reduzida no planejamento; } \\
\text { foco na execução. }\end{array}$ & $\begin{array}{l}\text { Ressignificação: ênfase crescente no plane- } \\
\text { jamento. }\end{array}$ \\
\hline Gestão do tempo & $\begin{array}{l}\text { Foco no curto prazo e gestão } \\
\text { ineficiente do tempo. }\end{array}$ & $\begin{array}{l}\text { Manutenção do traço, aguçado por pressões } \\
\text { ambientais (instabilidade e pressão por } \\
\text { agilidade, nova nuança). }\end{array}$ \\
\hline Autoritarismo & $\begin{array}{l}\text { Submissão a posições de poder, } \\
\text { respeito à autoridade. }\end{array}$ & Manutenção do traço. \\
\hline $\begin{array}{l}\text { Aversão a } \\
\text { conflitos }\end{array}$ & $\begin{array}{l}\text { Desconforto diante de confrontos } \\
\text { abertos. }\end{array}$ & Manutenção do traço. \\
\hline $\begin{array}{l}\text { Postura de } \\
\text { expectador }\end{array}$ & $\begin{array}{l}\text { Falta de autodeterminação; } \\
\text { transferência e diluição de } \\
\text { responsabilidades. }\end{array}$ & Manutenção do traço. \\
\hline Cordialidade & $\begin{array}{l}\text { Comportamento superficialmente } \\
\text { amável e simpático. }\end{array}$ & $\begin{array}{l}\text { Manutenção do traço: dificuldade para dizer } \\
\text { não. }\end{array}$ \\
\hline
\end{tabular}

Uma análise mais aprofundada das características pré e pós-globalização apontadas nos quadros 2 e 3 permite observar a seguinte situação. Por um lado, o ambiente institucional do país é visto ainda como algo predominante- 
mente instável e imprevisível, há pouco planejamento das atividades e ações, pouca sistematização e padronização de ações, muita orientação à flexibilidade, à criatividade e à improvisação e uma orientação predominante ao curto prazo. Esses elementos caracterizam a cultura organizacional atual e a gestão praticada no país como algo predominantemente desestruturado, desorganizado e improvisado. As relações entre as pessoas, por sua vez, são permeadas pela desigualdade de poder, pelo autoritarismo, pelo personalismo e pela necessidade de evitar conflitos, configurando uma gestão que tende a focar mais nas pessoas do que nos resultados. E, no que se refere à plasticidade, isto é, à permeabilidade do país aos referenciais estrangeiros, é possível verificar ainda a adoção acrítica desses referenciais. Essas características em conjunto configuram o estilo atual como paternalista, paroquial e pré ou antimoderno (Adler, 2002; Motta, 1996).

Por outro lado, as características pós-globalização dos traços culturais permitem observar um país, nas últimas décadas (1980 e 1990 principalmente), aberto à globalização econômica e à internacionalização dos negócios. Houve desde esse período a vinda de multinacionais ao país e a importação de referenciais estrangeiros para a gestão. Os gestores brasileiros tornaramse mais cosmopolitas, modernos e abertos a conceitos e modelos internacionalmente disseminados. Essa inclinação à internacionalização dos negócios impulsionou também aspectos como a orientação a resultados e a performance, a busca por dimensões mais objetivas da gestão como sistematizações e padronizações e o crescimento da utilização de técnicas de planejamento e estruturação de ações a médio ou longo prazos. A incorporação de referenciais estrangeiros na gestão local ainda acontece, porém, com o crescimento de uma posição crítica e com a valorização das práticas originadas localmente. A visão com relação ao planejamento é a de que sua utilização e incorporação às ações do dia-a-dia, embora reduzidas, comparativamente a outros países, têm crescido significativamente em termos históricos. A visão atual dos traços culturais na gestão das organizações revela uma gestão mais moderna e internacionalizada.

A situação acima descrita revela que coexistem na gestão praticada atualmente elementos tradicionais da cultura organizacional brasileira e que configuram um estilo paternalista, paroquial e pré-moderno de gestão e elementos "novos" ou ressignificados advindos do contexto internacional que configuram uma gestão internacional e moderna. Geralmente, a conciliação entre o que é global e internacional com o que é local é considerada um paradoxo importante e crucial com o qual as organizações hoje em dia se deparam. Os caminhos mais freqüentes para a resolução desse paradoxo são a inclina- 
ção a um dos pólos (global ou local) ou a adoção de uma posição equilibrada entre eles (Cunha e Cunha, 2000). No entanto, o que se observa para a gestão atualmente praticada no Brasil seria mais do que uma situação de simples equilíbrio entre elementos globais e locais. Observa-se que há o acompanhamento dos referenciais internacionais, mas que esses referenciais não seriam simplesmente adaptados (situação de equilíbrio). O quadro revelado neste artigo sugere que a gestão praticada atualmente no país pode ser caracterizada por três elementos centrais essenciais: o caráter transitório, o hibridismo e a ressignificação.

O caráter transitório refere-se a um sistema cultural em transformação, cuja dinâmica evolutiva possui como vetores principais as forças para a globalização e internacionalização dos negócios (e, conseqüentemente, pressões para adoção de práticas internacionais de gestão) e as condições institucionais e culturais do país (que freqüentemente constituem barreiras à adoção das práticas internacionais de gestão e que buscam preservar o local).

O hibridismo é fruto desse caráter transitório e significa a convivência entre traços culturais cuja visão atual (pós-globalização) manteve-se igual à visão anterior (pré-globalização) como, por exemplo, personalismo, desigualdade de poder, flexibilidade, autoritarismo e traços cuja visão atual difere (havendo novas nuanças ou ressignificações) da visão anterior como, por exemplo, o planejamento, o formalismo e a orientação a resultados. Essa convivência indica a justaposição de sistemas de valores nacionais e internacionais (aparentemente antagônicos) como comentou Albert e Whetten (1985); remete a uma nova configuração cultural originada pela identificação simultânea de elementos de culturas anteriormente distintas (nacionais e internacionais) como colocaram Burke (2003) e Canclini (2003); aponta a não-substituição integral dos sistemas locais pelos internacionais (Calás e Arias, 1997; Canclini, 2003); evidencia a importação de referenciais estrangeiros e a convivência com referenciais nacionais (Caldas e Wood, 2000); e dá lugar a uma formação social e organizacional fragmentada, heterogênea e múltipla, como indicou Calás e Arias (1997) e Steuer (2006).

A ressignificação que alguns traços apresentaram é fruto dessas duas dinâmicas — originadas pelo caráter transitório e pelo hibridismo - e implica constantes alterações nos traços culturais. Grande parte dessas ressignificações e novas nuanças nos traços significam a atuação de elementos globais em suas manifestações locais (Hermans e Kempten, 1998), como por exemplo a noção de jeitinho como um comportamento pouco profissional ou amador, a maior orientação a resultados e ao planejamento organizacional e a crescente adoção de sistematizações e padrões operacionais e gerenciais superiores. 
É preciso colocar, por fim, que as condições apresentadas para o quadro da gestão praticada no país é de difícil apreensão, uma vez que diferentes atores podem atribuir diferentes significados aos traços culturais em diferentes momentos.

\section{Comentários finais}

Este artigo teve como objetivo contribuir para a sistematização do quadro sobre traços da cultura organizacional brasileira atualmente. A comparação entre os estudos anteriores sobre cultura organizacional brasileira e os resultados do presente estudo revelou um quadro híbrido, típico de um período de transição, e caracterizado pela convivência entre traços culturais pré-globalização e pós-globalização.

Naturalmente, o caráter exploratório e qualitativo do estudo não permite generalizações, especialmente se considerarmos a grande extensão territorial e a diversidade cultural do país. Entretanto, os resultados obtidos são suficientes para indicar tendências de transformações nos traços da cultura organizacional local, assim como deduzir algumas implicações para a prática gerencial.

Em primeiro lugar, é preciso reconhecer as diferenças culturais. Um profissional recém-chegado ao Brasil talvez identifique nas práticas locais transposições diretas daquelas práticas adotadas nos países desenvolvidos. No entanto, além da superfície, os traços culturais que permeiam as relações pessoais e profissionais podem ser bastante distintos. Por exemplo: um executivo norte-americano poderá estranhar a alta distância do poder, a diluição da autoridade e a aversão a conflitos. Mas, se abandonar a posição etnocêntrica e reconhecer as raízes das diferenças, provavelmente conseguirá definir estratégias pessoais de adaptação e de ação.

Em segundo lugar, é preciso estar atento para o caráter híbrido da cultura organizacional. Tal condição pode implicar na convivência, em uma mesma organização, de grupos com distintos traços culturais. Por exemplo, um banco brasileiro adquirido por um banco europeu poderá conter áreas nas quais o personalismo e a alta distância do poder são traços marcantes e a orientação para resultados é um traço tênue, enquanto em outras áreas a situação é inversa. Saber identificar tais subculturas é algo essencial para atendimento dos objetivos organizacionais.

Em terceiro lugar, é preciso estar atento para o caráter transitório dos traços culturais e para as tensões originadas por esse movimento evolutivo. 
Gestores atuando no Brasil vêem-se constantemente diante de pressões contraditórias: de um lado, eles são pressionados pelas forças competitivas e buscam favorecer traços associados ao momento pós-globalização, tais como valorização do planejamento e da gestão do tempo; por outro lado, podem conviver com pares e líderes formados em ambientes organizacionais pré-globalização, pouco afeitos à disciplina exigida pelo novo ambiente.

Finalmente, é preciso estar atento à complexidade e à ambigüidade dos sistemas culturais. A densa textura que caracteriza a cultura organizacional brasileira pode não se revelar a não ser mediante um processo longo de observação e análise. Naturalmente, alguns traços culturais, como a cordialidade, o personalismo e o jeitinho podem ser de fácil observação. Outros, porém, podem exigir experiências e olhares mais aprofundados. No entanto, a compreensão dos sistemas culturais é essencial para orientar a ação gerencial, evitar frustrações e viabilizar a implantação bem-sucedida de projetos transformacionais.

\section{Referências bibliográficas}

ADLER, N. J. International dimensions of organizational behavior. Cincinnati, OH: South Western, 2002.

ALBERT, S; WHETTEN, D. A. Organizational identity. Research in Organizational Behavior, v. 7, p. 263-297, 1985.

ALCADIPANI, R.; CRUBELLATE, J. M. Cultura organizacional brasileira: generalizações improváveis e conceituações imprecisas. Revista de Administração de Empresas, v. 43, n. 2, p. 64-77, 2003.

ASHCRAFT, K. L. Organized dissonance: feminist bureaucracy as hybrid form. Academy of Management Journal, v. 4, n. 6, p. 1301-1322, 2001.

BARBOSA, L. O jeitinho brasileiro: a arte de ser mais igual que os outros. Rio de Janeiro: Campus, 1992.

BARDIN, L. Análise de conteúdo. Lisboa: Edições 70, 1977.

BARROS, T.; PRATES, M. O estilo brasileiro de administrar. São Paulo: Atlas, 1996.

. ; CANÇADO, V. L. Aquisições: um perfil das operações no Brasil. Caderno de Idéias, n. 27. Minas Gerais: FDC, 2003. 
BERTERO, C. O.; KEINERT, T. A evolução da análise organizacional no Brasil (19611993). Revista de Administração de Empresas, v. 34, n. 3, p. 81-90, 1994.

BOJE, D. M. Narrative methods for organizational and communication research. London: Sage Publications, 2002.

BORYS, B; JEMISON, D. Hybrid arrangements as strategic alliances: theoretical issues in organizational combinations. Academy of Management Review, v. 14, n. 2, p. 234-249, 1989.

BURKE, P. Hibridismo cultural. São Leopoldo: Unisinos, 2003.

CALÁS, M. B.; ARIAS, M. E. Compreendendo as organizações latino-americanas: transformação ou hibridização? In: MOTTA, F. C. P.; CALDAS, M. P. (Coords.). Cultura organizacional e cultura brasileira. São Paulo: Atlas, 1997.

CALDAS, M. Santo de casa não faz milagre: condicionantes nacionais e implicações organizacionais da fixação brasileira pela figura do "estrangeiro". In: . (Coords.) Cultura organizacional e cultura brasileira. São Paulo: Atlas, 1997. .; WOOD JR., T. Fads and fashions in management: the case of ERP. Revista de Administração de Empresas, v. 40, n. 3, p. 8-17, 2000.

COSTA, A. L. Cultura brasileira e organização cordial: ensaio sobre a Gaviões da Fiel. In: MOTTA, F. C. P.; CALDAS, M. P. (Coords.). Cultura organizacional e cultura brasileira. São Paulo: Atlas, 1997.

CRESWELL, J. W. Research design - qualitative, quantitative and mixed methods approaches. Thousand Oaks, CA: Sage Publications, 2003.

CUNHA, M. P. Adopting or adapting? The tension between local and international mindsets in Portuguese management. Journal of World Business, v. 40, n. 2, p. 188-202, 2005.

.; CUNHA, J. V. Globalization and the dialetics of managerial knowledge. In: INTERNATIONAL CONFERENCE MANAGERIAL KNOWLEDGE BETWEEN GLOBALIZATION AND LOCAL CONTEXTS. Proceedings... Roma: Luiss University, 2000.

DAMATTA, R. O que faz do Brasil, Brasil? 5. ed. Rio de Janeiro: Rocco, 1991.

DAVEL, E.; VASCONCELOS, J. Gerência e autoridade nas empresas brasileiras: uma reflexão teórica e empírica sobre a dimensão paterna nas relações de trabalho. In: MOTTA, F. C. P.; CALDAS, M. P. (Coords.). Cultura organizacional e cultura brasileira. São Paulo: Atlas, 1997.

ELIS, P.; CARRIERI, A. P. A percepção dos executivos expatriados italianos sobre a cultura brasileira. In: ENANPAD, 29. Anais... Brasília: Brasil, 2005. 
EMRICH, C. G.; DENMARK, F. L.; HARTOG, D. N. Cross-cultural differences in gender egalitarianism: implications for societies, organizations and leaders. In: HOUSE, R. J. et al. Culture, leadership and organizations - the Globe Study of 62 societies. London, UK: Sage Publications, 2004.

FREITAS, A. B. Traços para uma análise organizacional. In: MOTTA, F. C. P.; CALDAS, M. P. (Coords.). Cultura organizacional e cultura brasileira. São Paulo: Atlas, 1997.

FREITAS, M. E. Cultura organizacional: formação, tipologias e impactos. São Paulo: Makron Books, 1991.

GONÇALVES, G. A.; MIURA, I. K. Executivo expatriado: fatores que afetam o ajustamento internacional. In: ENANPAD, 26. Anais... Salvador, Brasil, 2002.

CANCLINI, N. G. Notícias recientes sobre la hibridación. Revista Transcultural de Música. v. 7, 2003. Disponível em: <www.sibetrans.com/trans/trans7/canclini. htm >. Acesso em: 28 fev. 2006.

HALL, E. T. The silent language. New York Fawcett, 1959.

. The silent language of overseas business. Harvard Business Review, v. 38, n. 3, p. 87-95, 1960.

. A dimensão oculta. Rio de Janeiro: Francisco Alves, 1977.

HERMANS, H. J.; KEMPEN, H. J. Moving cultures: the perilous problems of cultural dichotomia in a globalizing society. American Psychologist, v. 53, n. 10, p. 11111120, 1998.

HOFSTEDE, G. Cultures and organizations: software of the mind. London, UK: McGraw-Hill, 1997.

. Culture's consequences. Comparing values, behaviors, institutions and organizations across nations. Thousand Oaks, CA: Sage, 2001.

HOMEM, I. D.; TOLFO, S. R. Gestão intercultural: perspectivas para o ajustamento de executivos expatriados. In: ENANPAD, 28. Anais... Curitiba, Brasil, 2004.

HOUSE, R. J. et al. Culture, leadership and organizations - The Globe Study of 62 societies. London, UK: Sage Publications, 2004.

KABASAL, H.; BODUR, M. Humane orientation in societies, organizations, and leader attributes. In: HOUSE, R. J. et al. Culture, leadership and organizations - The Globe Study of 62 societies. London, UK: Sage Publications, 2004.

LAURENT, A. The cultural diversity of western conceptions of management. International Studies of Management and Organizations, v. 13, n. 1-2, p. 75-96, 1981. 
MARSHAL, C.; ROSSMAN, G. B. Designing qualitative research. Thousand Oaks: Sage, 1999.

MATHEUS, T. B. Uma discussão psicanalítica sobre o imaginário da lei no Brasil. In: MOTTA, F. C. P.; CALDAS, M. P. (Coords.). Cultura organizacional e cultura brasileira. São Paulo: Atlas, 1997.

MIRANDA, J. C.; MARTINS, L. Fusões e aquisições de empresas no Brasil. Economia e Sociedade, v. 14, p. 67-88, 2000.

MOTTA, F. C. P. Cultura e organizações no Brasil (Relatório de pesquisa n. 15/1996). São Paulo: FGV-Eaesp, 1996.

.; ALCADIPANI, R. Jeitinho brasileiro, controle social e competição. Revista de Administração de Empresas, v. 39, n. 1, p. 6-12, 1999.

.; CALDAS, M. Cultura organizacional e cultura brasileira. São Paulo: Atlas, 1997.

.; ALCADIPANI, R.; BRESLER, R. Estrangeirismo como segregação nas organizações. Revista de Administração Contemporânea, v. 5, número especial Eneo, 2001.

PIETERSE, J. N. Globalization as hybridization. Internacional Sociology, v. 9, n. 2, p. 161-184, 1994.

SCHEIN, E. H. Organizational culture and leadership. 2. ed. San Francisco: JosseyBass Inc. Publishers, 1992.

STEUR, R. S. Hibridização e hibridismos organizacionais: estudo de caso em contexto de integração pós-aquisição. Dissertação (Mestrado) — Escola de Administração de Empresas de São Paulo, Fundação Getulio Vargas, São Paulo, Brasil, 2006.

TRINCHES, D. Fusões, aquisições e outras formas de associação entre empresas no Brasil. Revista de Administração, v. 31, n. 1, p. 14-31, 1996.

TROMPENAARS, A. Nas ondas da cultura: como entender a diversidade cultural nos negócios. São Paulo, Brasil: Educator, 1993.

URDAN, F. T.; URDAN, A. T. Estilos gerenciais e agrupamento de cultura nacional: brasileiros versus europeus latinos e anglo-saxões. In: ENANPAD, 25. Anais... Campinas, Brasil, 2001.

VERGARA, S.; MORAES, C.; PALMEIRA, P. Cultura brasileira revelada no barracão de uma escola de samba: o caso da família imperatriz. In: MOTTA, F. C. P.; CALDAS, M. P. (Coords.). Cultura organizacional e cultura brasileira. São Paulo: Atlas, 1997. 
WOOD, T.; CALDAS, M. Antropofagia organizacional. Revista de Administração de Empresas, v. 38, n. 4, p. 6-17, 1998.

.; __ Adopting imported managerial expertise in developing countries: the Brazilian experience. Academy of Management Executive, v. 16, n. 2, p. 18-32, 2002.

; PAES DE PAULA, A. P. Pop-management: MBAs no Brasil (Relatório de pesquisa n. 25/2002). São Paulo: FGV-Eaesp, 2002. 